\title{
Employee Mental Illness: Moving Towards a Dominant Discourse in Management and HRM
}

\author{
Mirella Sarah De Lorenzo ${ }^{1}$ \\ ${ }^{1}$ Department of Leadership \& Management, Faculty of Business \& Law, Swinburne Business School, \\ Swinburne University of Technology, Australia \\ Correspondence: Mirella S De Lorenzo (Romanella), Swinburne University of Technology, Australia. E-mail: \\ mromanella@swin.edu.au
}

Received: August 25, 2014

Accepted: October 14, 2014

Online Published: November 22, 2014

doi:10.5539/ijbm.v9n12p133

URL: http://dx.doi.org/10.5539/ijbm.v9n12p133

\begin{abstract}
On a global scale, mental illness affects on average one in five employees in any twelve month period, and is well represented in the medical research literature as a dominant discourse. However, its presence in management and human resource management (HRM) research literature, while certainly on the rise, is less prevalent than it is in medical and related areas of research. At the same time, discussion of employee mental illness and its effects on employee performance and/or attendance, barely rates a mention in management and HRM textbooks, nor is it a common part of the curricula for university and other forms of higher education seeking to equip our future managers and HRM staff with the necessary skills and knowledge to be effective leaders. This paper will show that employee mental illness is a pervasive element of all workplaces, and as a consequence, policies to manage this phenomenon are not only vital, but overdue. Furthermore, it will be posited that this subject requires immediate inclusion in the teaching programs and textbooks of our future managers and HRM staff, and should be elevated from relative obscurity in such offerings to the status of a dominant discourse.
\end{abstract}

Keywords: Mental illness, hidden illness, discourse, presenteeism

\section{Introduction}

While the issue of mental illness in the workplace is gaining ground in management literature, it continues to lag behind research from medical disciplines, despite the fact that on average, $17 \%$ to $20 \%$ of employees in western countries attend work with a common mental illness each year (MHCC, 2012; SAMHSA, 2010; ABS, 2007). The virtual absence of this subject from text books and university syllabi designed to prepare our future managers and human resource management (HRM) staff to deal with all issues that affect an employee's work is astonishing (Sinclair \& O’Regan, 2007; Smith, 2006; De Lorenzo, 2003). Media portrayals of mental illness add to the belief system that its incidence is low and almost always a feature of inherently hostile persons who are less likely to be in paid employment (Edney, 2004; Francis, Pirkis, Dunt \& Blood, 2001). Moreover, as most employees with a mental illness make the deliberate choice to not disclose these disorders (Rüsch, Corrigan, Todd \& Bodenhausen, 2010; Munir, Leka \& Griffiths, 2005; Dewa, Lesage, Goering \& Caveen, 2004), even when facing performance management concerns for output and/or attendance issues resulting from hidden mental illness (De Lorenzo, 2013), managers need to be readily aware of the size of this problem so that they can formulate policies for undisclosed employee mental illness. Given the paucity of information about employee mental illness, operational managers and HRM staff are typically forced to piece together whatever information they can from the internet, media, societal views, anecdotal accounts and personal reading (Sinclair \& O’Regan, 2007). This paper will show that the effects of employee mental illness in the workplace warrants immediate insertion into mainstream management and HRM education and textbooks, rather than maintaining it in its current fashion as a dialogue that is fragmented and incomplete in our training programs (Fee, 1999). This paper begins by outlining the prevalence employee mental illness, and then reviews workplace functional issues associated with mental illness and strategies for its management, showing the importance of endowing employee mental illness as a dominant discourse, in the same manner as areas such as motivation and leadership currently claim in management and HRM textbooks.

\section{A Fragmented Discourse}

Foucault (Fee, 1999) noted that lack of information is sufficient to relegate a topic to the status of a series of 
fragmented conversations, all of which contribute to a dialogue, but that the dialogue is frustrated by its incompleteness. This is the case in relation to employee mental illness, as it rarely surfaces in textbooks and teaching syllabi for students of management and HRM, although it is prominently regarded by the World Health Organisation (WHO) as a discourse that is dominant and of extreme significance among medical authorities globally (Jakubec, 2004). Meanwhile, research consistently shows that the incidence of employee mental illness in the global labour force is on average as high as $17 \%$ to $20 \%$ in any calendar year, depending on how it is measured (MHCC 2012; SAMHSA 2010; ABS, 2007), showing that its presence in workplaces, is significant. Furthermore, studies employing diagnostic questionnaires such as those undertaken by the Australian Bureau of Statistics (ABS, 2007) have found that the incidence of common mental illnesses in the workplace such as anxiety disorders, affective disorders such as depression and substance use disorders affects $20.3 \%$ (ABS, 2007) of employees in any calendar year, with the full time workforce sustaining $19.3 \%$ of employee mental illnesses and part-time employees 22.1\% (ABS, 2007).

One of the influences that may account for fragmentation of discourse attention at the workplace level may be associated with the fact that disclosure rates for mental illness are very low among affected employees (Rüsch, et al., 2010; Munir, et al., 2005; Dewa, et al., 2004) such that managers and HRM staff are not accustomed to commonly hearing that a fifth of their workforce has some form of mental disorder. Reasons for non-disclosure are typically due to institutionalised and self-imposed stigma and/or concerns in relation to career damage (Corrigan, Todd and Bodenhausen, 2010; Rüsch et al., 2010; Barney, Griffiths, Christensen and Jorm, 2009; Goldberg, Killeen and O’Day, 2005; Quinn, Kahng and Crocker, 2004; Link, Yang, Phelan and Collins, 2004; Hickie, Groom \& Davenport, 2004; De Lorenzo, 2003; Glozier, 1998). Research in relation to disclosure when it is voluntary, and not a feature of assisted employment, show that at least as many as three quarters of employees with any chronic illness, including anxiety and depression, will either not disclose, or disclose only as much as is needed for accommodation of their illness (Munir et al., 2005).

\section{Workplace Features of Employee Mental Illness}

On any given work day, on average one in five or so employees attend work with a common mental illness (MHCC, 2012; SAMHSA, 2010; ABS, 2007). For some employees, disclosure is not an issue that needs to be hidden, while for most employees, it is a major concern that they believe may result in future career damage or negative stereotyping (Barney et al., 2009; Munir et al., 2005). Diagnostic surveys of mental illness also reveal that large numbers of employees may not know they have a common psychiatric disorder such as anxiety, depression or substance use disorder (ABS, 2007). Meanwhile, as managers and HRM staff are not normally trained to recognise or understand the prevalence and features of common mental illnesses in the workplace when such illnesses impact negatively on employee performance and/or attendance, concealment serves to hide the true causes of impaired work outcomes (De Lorenzo, 2013). In fact, both deliberate concealment and/or unknown mental illness that impacts negatively in employee work outcomes, may be viewed as poor work ethic and incorrectly managed with employee control policies such as performance management policies, which have the capacity to exacerbate the underlying causal issues of such illnesses (De Lorenzo, 2013).

\subsection{Costs}

The costs of mental illness in the workplace have been found to be far ranging, with estimates in the US alone of $\$ 100$ billion in direct care costs, and for serious mental illness lost earnings of \$193 billion (Mark, Levit, Coffey, McKusick, Harwood, King, Bouchery, Genuardi, Vandivort-Warren, Buck Corrigan, Todd and Bodenhausen, 2010; Ryan, 2007). The International Labour Organisation (ILO) and the World Health Organisation (WHO) have jointly found the costs of mental illness, particularly absenteeism, in the workplace to be high and rising (ILO \& WHO, 2000). Meanwhile, absenteeism due to depression was found to be in excess of 200 million lost days annually (ILO, 2000). When examining employee fitness for work, cognitive impairment and other functional aspects of symptom manifestation of depression and or anxiety reveal that employee ability to undertake normal work duties can be compromised at some level (Harvard, 2010).

\subsection{Employee Concealment}

According to a recent study by Peterson, Nandika and Collings (2011), who interviewed twenty-two employees with a mental illness, deliberate concealment of mental illness is common and conformed to other research findings which show that non-disclosure is employed as a strategy to forestall any possible discrimination or negative labelling (Corrigan, Todd and Bodenhausen, 2010; Government of Canada, 2006; Hickie, Groom and Davenport, 2004). In their own study of career concerns, the Government of Canada found in a 2002 survey that over $50 \%$ of respondents stated they had been adversely affected in their workplace by disclosing they had a mental illness (Government of Canada, 2006). Concerns about being labelled as unstable is another factor that 
adds to non-disclosure (Krupa, Kirsh \& Gewurtz, 2009), while societal and self-imposed stigma continues to greatly reduce disclosure (Barney et al., 2009; Link et al., 2004; Quinn et al., 2004). In a pertinent study of twenty employees suffering with mental health issues, Moll, Eakin, Franche and Strike (2013) found that only six of the subjects had accessed mental health sick leave, showing that even when such leave is available to deal with mental illness, more than large numbers of employees are unwilling to take it up.

Corrigan and Lundin (2001) outline the differing levels of disclosure, advocating selective disclosure as the best strategy for employees seeking to manage their illness. This entails determining who has to know, and how much they need to know. Accordingly, employees with a mental illness may decide to disclose to someone in their human resource area, to their immediate supervisor, or to simply note they have an unspecified medical condition (Corrigan \& Lundin, 2001). Such a strategy, which Munir et al. (2005) note takes place in practice, recognises that discrimination and stigma are often intertwined, affecting the decision to disclose any illness. Such views are not alarmist but rather in line with other research studies showing that the issues of stigma and career damage are uppermost in the minds of employees who do not disclose they have a mental illness (Corrigan, Janessa \& Shapiro, 2010; Rüsch et al., 2010; Corrigan et al., 2010; Hickie et al., 2004; Glozier, 1998).

\subsection{Functional Issues}

In relation to cognition, that is, the ability to reason, concentrate, recall information and make decisions, research demonstrates that this area is often compromised to some extent when a person sustains a mental illness (Harvard, 2010; Elliott, Sahakian, Herrod, Robbins \& Paykel, 1996 and 1997). Meanwhile, employee ability to attend work is often impacted (Birnbaum et al., 2010; Seymour 2010; De Lorenzo, 2003; Lim, Sanderson Corrigan, Todd \& Bodenhausen, 2010; Andrews, 2000) and sickness presenteeism, where illness affects an employee's ability to undertake normal work duties, is often compromised, with studies showing it to be normally far more costly than absenteeism (Dewa et al., 2004; Begg, Vos, Barker, Stevenson, Stanley \& Lopez, 2007; Druss, Rosenheck \& Sledge, 2000).

Symptoms of anxiety can include aches and pains, passive mood constant worry, restlessness, lowered energy levels and intrusive thoughts which have the capacity to intrude into the affected person's normal sleep and wake cycle affecting normal role function (Harvard, 2010). In their empirical study of employees, managers and support staff, Haslam, Brown, Atkinson and Haslam (2005) also found that employees living with anxiety and depression commonly noted that they felt quite unwell, were less able to undertake robust decision-making, with many detailing excessive tiredness, dizziness, nausea, poor levels of concentration, major mood swings and a pronounced lack of interest in their work. Such findings equate with common symptoms reported by persons suffering from anxiety and/or depression (Harvard, 2010).

In their review of US Dow company employees, Collins, Baase, Sharda, Ozminkowski, Nicholson, Billotti, Turpin, Olson, and Berger (2005) utilised a range of company data that included employee pharmacological use, responses to a questionnaire about presenteeism, and a range of health risk factors such as smoking status, finding that $65 \%$ of respondents reported having one or more chronic health conditions that resulted in an average loss in attendance hours of 0.9 to 5.9 hours per month, but a much higher level of presenteeism resulting in $17.8 \%$ to $36.4 \%$ reduction in functional ability to work each month when present on the job.

When comparing depression to bipolar disorder, the latter has been found to have nearly three times the amount of functional work loss (Kessler, Akiskal, Ames, Birnbaum, Greenberg, Hirschfeld, Jin, Merikangas, Simon \& Wang, 2006). In a review of how depressive illnesses and bipolar disorder affected both attendance and employee output, Kessler et al. (2006) found that days lost as a consequence of presenteeism accounted for 35.3 days per year for employees with bipolar disorder, while employees with depression lost 18.2 days.

\subsection{Employer Concerns}

Concerns about hiring persons with a mental illness often centres on functional performance and emotional stability in the workplace (Kosyluk, Corrigan, Todd \& Bodenhausen, 2010; Landis, 2014; Diska \& Rogers, 1996). Meanwhile, employers with past experiences of hiring people with a mental illness or severe disability have been found to have more positive views about hiring such persons in the future (Kosyluk et al. 2014; Diska \& Rogers, 1996; Levy, Jessop, Rimmerman \& Levy, 1991). In their studies of employer hiring decisions concerning people with severe psychiatric disorders, Kosyluk et al., (2014) also noted that not only were past experiences associated with the hiring of persons with mental illness positive, they were also inversely related to previously held views of stigma, although employers demonstrated a much higher preference for hiring persons with physical rather than mental disability. Similarly, Unger (2002) points out that employer views in relation to hiring persons with a mental disorder indicated that they thought this would be problematic, and grouped such concerns with employees around issues related to expected displays of emotional disturbance. Similarly, Hand, 
Tryssenaar, William, and Gill (2006) found that one of the biggest concerns small business employers have is that prospective employees with a mental illness may have poor social skills and may be overly emotional in the workplace.

In their survey of human resource employers and immediate supervisors, Kaye, Jans and Jones (2011) found that issues which caused barriers to the employment and retention of employees with a disability were principally in relation to lack of knowledge about how to accommodate an employee with a disability, and concerns about possible future litigation. According to Tsang, Angell, Corrigan, Lee, Shi, Lam, Ji and Fung (2007), employer issues about mental illness are common in both western and non-western communities with their empirical research showing that there is greater concern in non-western organisations about perceived deficits to work ethic for employees with a mental illness than in western workplaces.

\section{Spotlight on Depression}

As a standalone illness, depression contains a number of features that warrant special attention as it poses unique effects on employee fitness for work, and leaving aside comparisons with bipolar disorder (Kessler et al., 2006), it appears to be the costliest form of mental illness (Harvard, 2010; Kessler, White, Birnbaum, Qiu, Kidolezi, Mallett \& Swindle, 2008). In a unique study which compared employees with depression to those with rheumatoid arthritis and a control group, employed persons with depression displayed far higher levels of functional deficits for most tasks including time management, interpersonal tasks, and non-physical job duties (Adler, McLaughlin, Rogers, Chang, Lapitsky Corrigan, Todd \& Bodenhausen, 2010; Lerner, 2006).

\subsection{Cognitive Impairment}

Studies of employees who experience a depressive illness show that they have considerable issues in relation to cognitive impairment which affects their ability to remain in paid employment (Harvard, 2010; Lim, 2008; Adler et al., 2006; Lim, et al., 2000). Bender and Farvolden (2008) note that while most people with depression are able to attend work, they are often prone to reduced ability to manage their time, and often take longer periods of time to undertake normal tasks, resulting in consequent losses in work productivity. Meanwhile, symptoms of depression, and also medication for its treatment, can result in cognitive impairment, lack of sleep and lethargy which have direct effects on ability to attend and function at optimum levels of performance in the workplace (Bender and Farvolden, 2008; Harvard, 2010). The extent to which this results in lost work time and/or presenteeism, begs the question about the efficacy of employers using screening devices to ensure affected employees are obtaining treatment (Bender \& Fardolden, 2008). Such tools would also ensure that untreated employees are at lower risk of suicide (Bender \& Fardolden, 2008), although Glozier (2002) reminds us that they should not be used to weed out people on the basis of illness.

\subsection{Job Loss}

In a careful review of how groups of employees respond to daily job challenges and work schedules, Lerner et al. (2004) studied 229 employees with depressive illnesses, 87 employees with rheumatoid arthritis and a control group of 187 healthy employees. Employees with depressive illnesses showed significantly higher rates of job loss six months after the study had commenced. At the end of the six months those employees with depression who were still in paid employment also showed noticeably higher rates of presenteeism, absenteeism and reduced productivity than both the healthy and rheumatoid arthritis groups (Lerner et al., 2004). Persons with depression are also more likely to be unemployed than persons without a psychiatric illness, have lower levels of job retention, and are also more prone to higher levels of job turnover (Lerner \& Henke, 2008; Lerner et al., 2004).

\subsection{Effects on Group Performance}

Clusters of employees with symptoms of depression can also result in poor group performance (Harvey, Glozier, Henderson, Allaway, Lithchfield, Holland-Elliot \& Hotopf, 2011). In fact, Harvey et al. (2011) found that after administering a depression screening tool via voluntary cold call telephone screening, 54\% of employees contacted scored positive for low level or sub-clinical symptoms of depression, revealing much higher levels of depression when lower elements of this disorder are included in forming a diagnosis. Meanwhile, in a review of patient use of medications to deal with diagnosed illnesses of anxiety and/or depression, Haslam et al. (2005) found that the side-effects of such medications often impaired work function leading many employees to discontinue their use. Haslam et al. (2005) further found that personal insights about being unwell, or how one's illness affected ability to work, was significantly compromised such that each person's decision to consult a medical doctor was precipitated by a family friend or relative, or an incident of such profundity that a medical diagnosis was needed to consider mental illness. 


\subsection{Concealment}

In the UK, the Mental Health Foundation (2009) via a study undertaken by Loughborough University found that while employees with serious medical conditions such as cancer or chronic heart disease are candid about revealing such illnesses, those who also experience depression are reluctant to mention that they are experiencing a mental disorder. The issue of poor societal knowledge and fragmentation of knowledge about mental illness contributes to this broken and incomplete discourse that struggles to gain acceptance in the training programs of our future managers (Fee, 1999).

\subsection{Impaired Work Outcomes}

In reviewing the extent to which full time employees attend work with a mental illness, Lim et al. (2000) found that the effect of mental illness on work outputs is high and often manifests as reduced employee output and/or presenteeism, with anxiety taking the greatest toll on employee output when measured as an aggregate effect. While anxiety disorders are far higher in frequency than other mental disorders (ABS, 2007), employees with depression are often found to have the highest per employee costs with higher levels presenteeism and absenteeism which is often a feature of significant cognitive impairment (Birnbaum, Kessler, Kelley, BenHamadi, Joish Corrigan, Todd \& Bodenhausen, 2010 Greenberg, 2010; Seymour, 2010; ILO, 2000).

Paulus and Yu (2012) note that persons with anxiety and/or depression experience significant deficits to judgment, including reduced risk taking, heightened sensitivity to losses and significantly reduced pleasure in obtaining a reward. Meanwhile, lack of information about employee mental illness continues to be a major hurdle in the management of this area, and also its disclosure by affected employees (MHCA, 2013). When considering how symptom severity actually affects attendance, the following account by a female clerk is striking by its candour in terms of functional ability to attend work (Haslam et al., 2005, p. 207):

I couldn't actually get out of bed in the morning and I'd frequently roll in at half nine, ten o'clock, and we're supposed to start at nine o'clock. But I just could not get out of bed. It was really, really hard ... dragging yourself into work. On a really bad day I'd be throwing up and shaking and I just couldn't come into work.

\section{Workplace Concerns and Expectations}

While the media portrayal of mental illness is consistently negative, adding to the fragmentation of knowledge and conversation about mental illness (Edney, 2004; Francis et al., 2001), it is imperative that managers and HRM staff are better informed about the functional deficits of mental illness per se. In this regard, it is important to note that psychiatric illnesses come in a range of symptoms and time frames that belie established stereotypes of societal construction. For instance, when considering how particular symptoms have the capacity to affect a person's ability to function in the workplace, factors such as cognition, attendance and safety are arguably the most common features of most mental illnesses, particularly those which are concealed, undiagnosed or not appropriately managed (De Lorenzo, 2013; Harvard, 2010).

\subsection{Moving Past Negative Stereotypes}

Lack of formal training in relation to employee mental illness can result in managers and HRM staff basing their management of such employees on non-traditional forms of knowledge that are open to error. According to the Mental Health Foundation (UK, 2009), 45\% of employees who experience physical illnesses develop depression, although most will find they feel too uncomfortable raising this with their immediate manager, even when depression impacts on their work. This reluctance to disclose is further compounded by lack of knowledge in workplaces about mental illnesses and an almost unfettered perpetuation of societal misinformation and stigma about mental illness (MHF, 2009; Mental Health Council of Australia, 2013). Moreover, media portrayals of mental illness in mainstream movies, television and newspapers, has been found to often invoke negative stereotypes of mental illness, thereby shaping society's views of these illnesses in a pejorative manner (Edney, 2004; Francis et al., 2001).

In two surveys of over 500 British employers concerning their knowledge and workplace practices of employees with a mental illness in 2006 and 2009 (cited in Little, Henderson, Brohan \& Thornicroft, 2011), it was found that while more employers are recognising that mental illness will affect their workplace, that the number of employers who believe they need additional support to deal with mental illness in the workplace has risen from 77\% (2006) to 88\% (2009). According to the Harvard Medical School (2010) not only is it important to be aware of the symptoms of mental illness in the workplace, it is also important to understand that such symptoms when they manifest in the workplace, may not be different to symptoms manifesting in other situations.

In addition to the scarcity of knowledge available to managers and HRM staff pertaining specifically to mental illness, it appears that another neglected knowledge base is how to manage employees with a primary physical 
illness who later develop a mental disorder (Mental Health Foundation, UK, 2009). In an extensive review of approximately 78,000 Australian employees with a range of illnesses, Holden, Scuffham, Hilton, Ware, Vecchio, and Whiteford (2011) found co-morbidity of physical and psychological illness often results in significant reductions to employee productivity, specifically via absenteeism and sickness presenteeism, showing that management of physical illness needs to also consider that a primary illness has the capacity to be intertwined with mental illness at some stage.

While the issue of presenteeism per se is gaining recognition, its association with mental illness is still fragmented (De Lorenzo, 2013, Sinclair \& 、 O’Regan, 2007). Reduced employee attendance, or absenteeism due to mental illness is costly, although as noted above, studies show that sickness presenteeism is far more costly (Collins, Baase, Sharda, Ozminkowski, Nicholson, Billotti, Turpin, Olson \& Berger 2005; Dew, Keefe Corrigan, Todd \& Bodenhausen, 2010; Small, 2005) with large numbers of employees compounding this by often choosing not to disclose by deferring to their concerns about stigma, privacy and other reservations rather than to disclose their illness for accommodation purposes (Munir, et al., 2005; Dewa et al., 2004).

\subsection{Employer Assisted Programs and Concerns about Disclosure}

When reviewing studies of assisted employment, disclosure is often not an option. In an interesting study in which $87 \%$ of respondents from a sample of managerial and professional employees who obtained work under an assisted employment program chose to disclose, Ellison, Russinova, MacDonald-Wilson, and Lyass (2003) found that nearly half later regretted doing so. Moreover, Ellison et al. (2003) noted that the reasons for disclosure were often related to accommodation requirements and the initial belief that this would be met benignly as often such employees were able to self-manage their illness. While the issue of accommodation can act to increase disclosure in relation to assisted employment programs, disclosure may not always be managed appropriately (Akabas, Corrigan, Todd \& Bodenhausen, 2010; Gates, 2000).

\section{Moving to Employee Mental Illness as a Dominant Discourse}

The twin issues of a fragmented discourse in relation to employee mental illness, and organisational inertia has contributed to an often ad hoc approach to the workplace management of a group of common mental disorders (anxiety disorders, affective disorders such as depression, and substance use disorders) that are often not declared or managed (De Lorenzo, 2013, ABS, 2007). In healthcare, while stress has been found to exact a high toll on this industry, there is a discourse of impregnability that almost refuses to consider that nurses may sustain a mental illness (Moll, 2014).When mental illness becomes a common part of the curricular for managers and HRM staff, then organisations will begin to implement a range of appropriate policies to deal with the relevant issues of this area; namely to increase employee diagnosis rates, ensure employees have confidential means of disclosing mental illness, ensure managers and HRM staff are trained in how to best manage employees with mental illness per se, and finally, how to reduce stigma impacting on employee disclosure decisions (De Lorenzo, 2013; ABS, 2007).

\subsection{Policy Development}

In reviewing specific mental illness disorders and findings, it is clear that lack of knowledge, combined with low employee disclosure rates and undiagnosed cases of mental illness, that HRM staff should be putting into place programs to manage these issues in all workplaces and not relying solely on local or national disability policies as these typically require employee disclosure for accommodation purposes (De Lorenzo, 2013). If mental illness was a dominant discourse in both management and HR areas of formal knowledge, all organisations could put into place a suite of appropriate policies. For instance, to improve employee self-diagnosis, free and fully confidential reliable online screening tools could be provided to staff. To ensure performance management issues are avoided for employees who choose to conceal a mental illness, steps could be taken to encourage employee disclosure along the lines of De Lorenzo's (2013) 'Buffer Stage' policies outlined below. Similarly, to better manage employees with a disclosed mental illness, managers would be provided with resources to ensure they carefully manage affected employees. The importance of such policies are immediately apparent by studies which show a range of functional issues for employees working with a mental illness, whether such illnesses are known, disclosed, or not disclosed (Dewa et al., 2004; Begg, Vos, Barker, Stevenson, Stanley \& Lopez, 2007; Druss, Rosenheck \& Sledge, 2000).

\subsection{Improving Information about Employee Mental Illness}

While the incidence and effects of mental illness in workplaces are not in dispute, lack of training in the professions of management and HRM means that employees who sustain a mental illness are not sufficiently serviced by managers trained to deal with these illnesses (De Lorenzo, 2013). However, the fact that mental 
illnesses are largely undisclosed, or undiagnosed, confers a sense that organisations need not concern themselves with providing specialist resources for this area of wellbeing (De Lorenzo, 2013). It is suggested that organisations can significantly reduce costs associated with presenteeism as a consequence of impaired functional performance, improve attendance, and improve safety by addressing the current lack of formal training in these areas. Many of the symptoms of mental illness correspond to those of poor work ethic, however workplace management of psychiatric symptoms vary considerably in comparison to how one would manage employees displaying poor work ethic (Waghorn, Chant, Lloyd \& Harris, 2009; Kessler, et al., 2008; Lim, 2008; Lim et al., 2000).

\subsection{Increasing Employee Disclosure}

To improve disclosure levels, a range of policies can be easily adopted, including the use of workplace materials such as posters and newsletters to de-stigmatise mental illness and to bring it into light as a commonly occurring illness that affects at least half of all persons at some stage in their life (ABS, 2007; ILO, 2000a) and reframing it as a normal illness (Brohan et al., 2012). In terms of undiagnosed psychiatric illness (Kessler et al, 2006; Elliott et al., 1997), the provision of reliable diagnostic online tests selected in consultation with psychiatric medical practitioners, could be made available on a wellness area of any workplace intranet, and also rolled out every few months in workplace newsletters. According to the American National Institutes of Health (NIH, 2007), screening for depression results in improvements to employee productivity and significantly lowers costs.

For employees who have a diagnosed mental illness, but who find disclosure too difficult a breach to consider, De Lorenzo (2013) has suggested use of "Buffer Stage" policies before moving to implement formal performance management policies to avoid applying a management improvement plan on employees with a hidden mental illness. These conceptualised policies include provision of confidential reporting of any illness to a designated member of HR, provision of flexible work hours, or two to three months off work at the employee's expense to allow employees to return to better health rather than imposing formal performance management policies on employees who may have a hidden mental illness (De Lorenzo, 2013). Lack of employee disclosure about mental illness impacts invisibly on performance management when managers and HR staff unknowingly apply a performance improvement plan on employees with hidden illness which will be doomed to fail (De Lorenzo, 2013).

\subsection{Reducing Stigma}

The use of education and information to challenge commonly held misconceptions about mental illnesses have been proposed by the ILO (2000a) as one of the most effective means of reducing stigma. In Scotland, a very successful means of undertaking this was with their "See Me" program that utilised educational materials and posters to increase the prominence of mental illness as something that affects more than a small number of employees (Scottish Government, 2012). Use of diagnostic systems to assist employees with a diagnosed mental illness has also been found to greatly assist in symptom relief by providing much needed information to employees with a mental illness (Farzanfar \& Finkelstein, 2012). Organisations which provide a fully confidential telephone based screening and resource program, allowing employees to engage safely and without concern about stigma or loss of confidentiality, fulfill an important role in the absence of improved knowledge about mental illness (Farzanfar \& Finkelstein, 2012).

\subsection{Promoting a Healthy Workplace}

In reviewing a range of workplace health promotional materials and resources in responding to sickness presenteeism, Cancelliere, Cassidy, Ammendolia and Cote (2011) found that many such programs had a positive effect on employees, with those using exercise being particularly successful. In relation specifically to depression, Cancellire et al. (2011) noted that depression screening for employees, mental health awareness training for supervisors, telephone outreach programs and the creation and maintenance of an environment of psychological safety produced very positive outcomes. In relation to psychological safety, Shain, Arnold and Germann (2012) suggest that the concept of psychological safety in the workplace has a special place as it serves to ensure that all steps have been taken by an organisation in order to ensure that employee psychological health is considered of extreme importance, and that policies are put into place accordingly.

\subsection{Mental Illness as an Accepted Discourse in the Training of Managers and HRM Staff}

There is no dispute about the data, employees with a mental illness are a significantly large sub group within any workplace (ABS, 2007). The shifting nature of this group, means that in any particular year, those who have a mental illness, may be substantially different to those from previous years, which reminds us that common mental illnesses affect close to one in two people over the course of a person's lifetime (ABS, 2007). The 
inclusion of mental illness in the training programs and textbooks of our future managers and HRM staff is not an area of debate, but one of a fragmented discourse that needs to be overcome immediately (Fee, 1999). In medicine and related areas, studies about mental illness and its effects on employee attendance and performance are part of an established discourse for this illness. By including materials about mental illness in mainstream management and HRM textbooks we would be in a better position to evaluate and endorse policies for the effective management of all forms of mental illness, known and unknown by employees, declared and concealed (De Lorenzo, 2013; Sinclair \& O’Regan, 2007; Smith, 2006). It is therefore imperative that in recognition of the prevalence and effects of employee mental illness, adverse workplace issues arising from these illnesses, and policies to manage disclosed, hidden and unknown mental illness need to be a normal mainstay of training and educational materials for our managers and HRM staff.

With textbooks in management and HRM concentrating on areas such as motivation and leadership theories for the purposes of positively affecting employee performance, and employee control polices outlining how to manage employees with poor attendance and/or performance, it is disingenuous to exclude hidden illness per se from the training materials of our future managers. It is misleading to give the impression that chronic illnesses (Munir et al., 2005) and mental illnesses in particular (MHCC, 2012; SAMHSA, 2010; ABS, 2007), must be sufficiently insignificant in prevalence and effects in the workplace, to exclude them in the training materials of managers and HRM staff.

\section{Conclusion}

Universities currently train managers and HRM students with careful attention to selected streams of knowledge, yet almost completely omit attention to employee mental illness, despite the fact that it forms a dominant medical discourse, with such illnesses affecting on average one if five employees (MHCC, 2012; SAMHSA, 2010; ABS, 2007). The current failure of most management and HRM textbooks to even mention employee mental illnesses is an indictment of the concerns noted by Fee (1999) about the disconnection between reality and imposed reality via socially contrived and fragmented discourses. This same disconnection can be found in our universities and reflects a myopic view about training by relying on textbooks that are not sufficiently comprehensive in relation to employee mental illness in the workplace (Sinclair \& O'Regan, 2007; Smith, 2006; De Lorenzo, 2003). As a consequence, our future managers and HRM staff need to be accurately and comprehensively informed about mental illness as it affects at least $17 \%$ to $20 \%$ of the workforce globally (MHCC, 2012; SAMHSA, 2010; ABS, 2007), is often hidden or not diagnosed, and significantly impacts on workplace costs. The adoption of mental illness as a dominant discourse within mainstream management and HRM textbooks, curricular and syllabi is now overdue and a necessity so that these illnesses can be appropriately managed rather than ignored and allowed to bask in the current quagmire of societal misinformation about workplace mental illness (De Lorenzo, 2003; Fee, 1999).

\section{References}

Adler, D. A., McLaughlin, T. J., Rogers, W. H., Chang. H., Lapitsky, L., \& Lerner, D. (2006). Job performance deficits due to depression. American Journal of Psychiatry, 163(9), 1569-1576. http://dx.doi.org/10.1176/appi.ajp.163.9.1569

Akabas, S. H., \& Gates, L. B. (2000). A social work role: Promoting employment equity for people with serious and persistent mental illness. Administration in Social Work, 23(3/4), 163-184. http://dx.doi.org/10.1300/J147v23n03_10

Austin, A. P., Mitchell, P., \& Goodwin, G. M. (2001). Cognitive deficits in depression. The British Journal of Psychiatry, 178, 200-206. http://dx.doi.org/10.1192/bjp.178.3.200

Australian Bureau of Statistics (ABS). (2007). National survey of mental health and wellbeing survey, Catalogue No 4326.0, Canberra, Australia. Retrieved from http://www.abs.gov.au/AUSSTATS/abs@.nsf/DetailsPage/4326.02007?OpenDocument

Barney, L. J., Griffiths, K. M., Christensen, H., \& Jorm, A. F. (2009). Exploring the nature of stigmatising beliefs about depression and help-seeking: implications for reducing stigma. BMC Public Health, 9(61), 1-11. http://dx.doi.org/10.1186/1471-2458-9-61

Begg, S., Vos, T., Barker, B., Stevenson, C., Stanley, L., \& Lopez, A. D. (2007). The burden of disease and injury in Australia 2003. Canberra: School of Population Health, University of Queensland, Brisbane, Australian Institute of Health and Welfare. AIHW Cat. No. PHE 82. Retrieved from http://www.aihw.gov.au/WorkArea/DownloadAsset.aspx?id=6442459747

Bender, A., \& Farvolden, P. (2008). Depression and the Workplace: A Progress Report. Current Psychiatry 
Reports, 10(1), 73-79. http://dx.doi.org/10.1007/s11920-008-0013-6

Birnbaum, H. G., Kessler, R. C., Kelley, D., Ben-Hamadi, R., Joish, V. N., \& Greenberg, P. E. (2010). Employer burden of mild, and severe major depressive disorders: mental health services utilization and costs, and work performance. Depression and Anxiety, 27(1), 78-89. http://dx.doi.org/10.1002/da.20580

Cancelliere, C., Cassidy, J. D., Ammendolia, C., \& Côté, P. (2011). Are workplace health promotion programs effective at improving presenteeism in workers? A systematic review and best evidence synthesis of the literature. BMC Public Health, 11, 1-11. http://dx.doi:10.1186/1471-2458-11-395

Collins, J. J., Baase, C. M., Sharda, C. E., Ozminkowski, R. J., Nicholson, S., Billotti, G. M., Turpin, R. S., Olson, M., \& Berger, M. L. (2005). The Assessment of Chronic Health Conditions on Work Performance, Absence, and Total Economic Impact for Employers. Journal of Occupational \& Environmental Medicine, 47(6), 547-557. http://dx.doi.org/doi:10.1097/01.jom.0000166864.58664.29

Corrigan, P. W., Janessa, R., \& Shapiro, J. R. (2010). Measuring the impact of programs that challenge the public stigma of mental illness. Clinical Psychology Review, 30(8), 907-922. http://dx.doi.org/10.1016/j.cpr.2010.06.004

Corrigan, P., \& Lundin, R. (2001). Don't call me nuts!: Coping with the stigma of mental illness. Tinely Park, IL: Recovery Press.

De Lorenzo, M. S. (2013). Employee Mental Illness: Managing the Hidden Epidemic. Employee Responsibilities and Rights Journal, 25(4), 219-238. http://dx.doi.org/10.1007/s10672-013-9226-x

De Lorenzo, M. S. (2003). Absenteeism: Work-Induced Stress Illnesses, and Hidden Mental Illnesses. PhD thesis, Monash University.

Dew, K., Keefe, V., \& Small, K. (2005). Choosing to work when sick: workplace presenteeism. Social Science \& Medicine, 60(10), 2273-2282. http://dx.doi.org/10.1016/j.socscimed.2004.10.022

Dewa, C. S., Lesage, A., Goering, P., \& Caveen, M. (2004). Nature and Amplitude of Mental Illness in the Workplace. Healthcare Papers, 5(2), 12-25. Discussion Paper. http://dx.doi.org/10.12927/hcpap.16820

Diska, E., \& Rogers, E. S. (1996). Employer concerns about hiring persons with psychiatric disability: Results of the employer attitude questionnaire. Rehabilitation Counseling Bulletin, 40(1), 31-44. http://dx.doi.org/10.1177/108835760201700101

Druss, B. G., Rosenheck, R. A., \& Sledge, W. H. (2000). Health and disability costs of depressive illness in a major U.S corporation. The American Journal of Psychiatry, 157(8), 1274-1278. http://dx.doi.org/10.1176/appi.ajp.157.8.1274

Edney, D. W., (2004). Mass Media and Mental Illness: Literature Review, Canadian Mental Health Association, Ontario. Retrieved from http://www.ontario.cmha.ca/files/2012/07/mass_media.pdf

Ellison, M. L., Russinova, Z., MacDonald-Wilson, K. L., and Lyass, A. (2003). Patterns and correlates of disclosure among professionals and managers with psychiatric conditions. Journal of Vocational Rehabilitation, 18(1), 3-13.

Elliott, R., Sahakian, B. J., Herrod, J. J., Robbins, T. W., \& Paykel, E. S. (1997). Abnormal response to negative feedback in unipolar depression: evidence for a diagnostic specific impairment. Journal of Neurology, Neurosurgery and Psychiatry, 63, 74-82. http://dx.doi.org/10.1136/jnnp.63.1.74

Elliott, R., Sahakian, B. J., Herrod, J. J., Robbins, T. W., \& Paykel, E. S. (1996). Neuropsychological impairments in unipolar depression: the influence of perceived failure on subsequent performance. Psychological Medicine, 26, 975-989. http://dx.doi.org/10.1017/S0033291700035303

Farzanfar, R., \& Finkelstein, D. (2012). Evaluation of a workplace technology for mental health assessment: A meaning-making process. Computers in Human Behavior, 28(1), 160-165. http://dx.doi.org/10.1016/j.chb.2011.08.022

Fee, D. (1999). Pathology and the Postmodern: Mental Illness as Discourse and Experience. London: Sage Publications.

Glozier, N. (2002). Mental ill health and fitness for work. Journal of Occupational \& Environmental Medicine, 59(10), 714-720. http://dx.doi.org/10.1136/oem.59.10.714

Glozier, N. (1998). Workplace effects of the stigmatization of depression. Journal of Occupational \& Environmental Medicine, 40(9), 793-800. http://dx.doi.org/10.1097/00043764-199809000-00008 
Goldberg, S. G., Killeen, M. B., \& O’Day, B. (2005). The Disclosure Conundrum: How People with Psychiatric Disabilities Navigate Employment. Psychology, Public Policy, and Law, 11(3), 463-500. http://dx.doi.org/10.1037/1076-8971.11.3.463

Government of Canada. (2006). The Human Face of Mental Health and Mental Illness in Canada. Cat.: HP519/2006E, ISBN: 0-662-43887-6. Retrieved from http://www.phac-aspc.gc.ca/publicat/humanhumain06/index-eng.php

Hand, C., Tryssenaar, J. A., William, A. (Editor) \& Gill, K. J. (Editor). (2006). Small Business Employer’s Views on Hiring Individuals with Mental Illness. Psychiatric Rehabilitation Journal, 29(3), 166-173. http://dx.doi.org/10.2975/29.2006.166.173

Harvard (Harvard Medical School). (2010). Mental health problems in the workplace, Harvard Mental Health Letter, February, Harvard Health Publications.

Harvey, S. B., Glozier, N., Henderson, M., Allaway, S., Lithchfield, P., Holland-Elliot, K., \& Hotopf, M. (2011). Depression and work performance: an ecological study using web-based screening. Occupational Medicine, 61(3), 209-211. http://dx.doi.org/10.1093/occmed/kqr020

Haslam, C., Brown, S. S., Atkinson, S., \& Haslam, R. A. (2005). Patients' experiences of medication for anxiety and depression: effects on working life. Family Practice, 21(2), 204-212. http://dx.doi.org/10.1093/fampra/cmh218

Hickie, I., Groom, G., \& Davenport, T. (2004). Investing in Australia's future: the personal, social and economic, benefits of good mental health. Canberra: Mental Health Council of Australia.

Holden, L., Scuffham, P. A., Hilton, M. F., Ware, R. S., Vecchio, N., \& Whiteford, H. A. (2011). Health-related productivity losses increase when the health condition is co-morbid with psychological distress: findings from a large cross-sectional sample of working Australians. BMC Public Health, 11(4), 417-425. http://dx.doi.org/10.1186/1471-2458-11-417

ILO (International Labour Office). (2000). Mental health in the workplace. Geneva: International Labour Office.

ILO (International Labour Office). (2000a). Mental health and work: impact, issues and good practices. Geneva: International Labour Office.

ILO \& WHO. (World Health Organisation). (2000). Mental health and work: impact issues and good practices. Monograph: International Labour Office.

Jakubec, S., (2004). The "World Mental Health" framework: Dominant discourses in mental health and international development, Canadian Journal of Community Mental Health.

Kaye, H. S., Jans, L. H., \& Jones, E. C. (2011). Why Don't Employers Hire and Retain Workers with Disabilities. Journal of Occupational Rehabilitation, 21(4), 526-536. http://dx.doi.org/10.1007/s10926-011-9302-8

Kessler, R. C., Akiskal, H. S., Ames, M., Birnbaum, H., Greenberg, P., Hirschfeld, R. M. A., Jin, R., Merikangas, K. R., Simon, G. E., \& Wang, P. S. (2006). Prevalence and effects of mood disorders on work performance in a nationally representative sample of U.S. workers. The American Journal of Psychiatry, 163(9), 15611568. http://dx.doi.org/10.1176/appi.ajp.163.9.1561

Kessler, R., White, L. A., Birnbaum, H., Qiu, Y., Kidolezi, Y., Mallett, D., \& Swindle, R. (2008). Comparative and Interactive Effects of Depression Relative to Other Health Problems on Work Performance in the Workforce of a Large Employer. Journal of Occupational and Environmental Medicine, 50(7), 809-816. http://dx.doi.org/10.1097/JOM.0b013e318169ccba

Kosyluk, K. A., Corrigan, P. W., \& Landis, R. S. (2014). Employer Stigma as a Mediator between Past and Future Hiring Behavior. Rehabilitation Counseling Bulletin, 57(2), 102-108. http://dx.doi.org/10.1177/0034355213496284

Krupa, T., Kirsh, B., \& Gewurtz, R. (2009). Understanding the stigma of mental illness in employment. Journal of Prevention Assessment \& Rehabilitation, 33(4), 413-425. http://dx.doi.org/10.3233/WOR-2009-0890

Lerner, D., \& Henke, R. M. (2008). What Does Research Tell Us About Depression, Job Performance, and Work Productivity? Journal of Occupational and Environmental Medicine, 50(4), 401-410. http://dx.doi.org/10.1097/JOM.0b013e31816bae50

Lerner, D., Adler, D. A., Chang, H, Lapitsky, L., Hood, M. Y., Perissinotto, C., Reed, J., McLaughlin, T. J., Berndt, E. R., \& Rogers, W. H. (2004). Unemployment, job retention, and productivity loss among 
employees with depression. Psychiatric Services, 55(12), 1371-1378. http://dx.doi.org/10.1176/appi.ps.55.12.1371

Levy, J. M., Jessop, D. J., Rimmerman, A., \& Levy, P. H. (1991). Employment of persons with severe disabilities in large businesses in the United States. International Journal of Rehabilitation Research, 14(4), 323-332. http://dx.doi.org/10.1097/00004356-199112000-00005

Lim, L. (2008). Depression, the Misunderstood Illness. Singapore: Armour Publishing.

Lim, D., Sanderson, K., \& Andrews, G. (2000). Lost Productivity Among Full-Time Employees with Mental Disorders. The Journal of Mental Health Policy and Economics, 3, 139-146. http://dx.doi.org/139146/10.1002/mhp.93

Link, B. G., Yang, L. H., Phelan, J. C., \& Collins, P. Y. (2004). Measuring mental illness stigma. Schizophrenia Bulletin, 30(3), 511-541. http://dx.doi.org/10.1093/oxfordjournals.schbul.a007098

Little, K., Henderson, C., Brohan, E., \& Thornicroft, G. (2011). Employers' attitudes to people with mental health problems in the workplace in Britain: changes between 2006 and 2009. Epidemiology and Psychiatric Sciences, 20(1), 73-81. http://dx.doi.org/10.1017/S204579601100014X

Mark T. L., Levit, K. R., Coffey R. M., McKusick, D. R., Harwood, H. J., King E. C., Bouchery E., Genuardi J. S., Vandivort-Warren R., Buck J. A., \& Ryan, K. (2007). National Expenditures for Mental Health Services and Substance Abuse Treatment, 1993-2003. SAMHSA Publication No. SMA 07-4227. Rockville, MD: Substance Abuse and Mental Health Services Administration, 2007. Retrieved from http://www.google.com.au/url?sa=t\&rct=j\&q=\&esrc=s\&frm=1\&source=web\&cd=1\&ved=0CB4QFjAA\&u rl=http\%3A\%2F\%2Fstore.samhsa.gov\%2Fshin\%2Fcontent\%2FSMA07-4227\%2FSMA074227.pdf\&ei=GaCzU7SKJMSrkQWTwIGICg\&usg=AFQjCNEm2_2Y9x_6_3sjCpyoH1Pp7jkHQg\&bvm= bv.70138588,d.dGI

Mental Health Commission of Canada (MHCC). (2012). Changing directions, changing lives: the mental health strategy for Canada. Calgary. Retrieved from http://strategy.mentalhealthcommission.ca/pdf/strategyimages-en.pdf

Mental Health Council of Australia (MHCA). (2013). Improving the employment participation of people with a disability in Australia, Discussion Paper, MHCA, Canberra.

Mental Health Foundation (MHF, UK). (2009). Returning to Work, The role of depression. Retrieved from http://www.mentalhealth.org.uk/content/assets/PDF/publications/returning_to_work.pdf?view=Standard

Moll, S. (2014). The web of silence: a qualitative case study of early intervention and support for healthcare workers with mental ill-health. BMC public health, 14(1), 1-13. http://dx.doi.org/10.1186/1471-2458-14138

Moll, S., Eakin, J. M., Franche, R., \& Strike, C. (2013). When Health Care Workers Experience Mental Ill Health, Institutional Practices of Silence. Qualitative Health Research, 23(2), 167-179. http://dx.doi.org/10.1177/1049732312466296

Munir, F., Leka, S., \& Griffiths, A. (2005). Dealing with self-management of chronic illness at work: predictors for self-disclosure. Social Science \& Medicine, 60(6), 1397-1407. http://dx.doi.org/10.1016/j.socscimed.2004.07.012

National Institutes of Health (NIH). (2007). Workplace Depression Screening, Outreach and Enhanced Treatment, Improves Productivity, Lowers Employer's Costs. NIH, News and Events. Retrieved from http://www.nimh.nih.gov/about/strategic-planning-reports/index.shtml

Paulus, M. P., \& Yu, A. J. M. (2012). Emotion and decision-making: affect-driven belief systems in anxiety and depression. Trends in Cognitive Sciences, 16(9), 476-483. http://dx.doi.org/10.1016/j.tics.2012.07.009

Peterson, D., Nandika, C., \& Collings, S. (2011). You don't look like one of them': Disclosure of mental illness in the workplace as an ongoing dilemma. Psychiatric Rehabilitation Journal, 35(2), 145-147. http://dx.doi.org/10.2975/35.2.2011.145.147

Quinn, D. M., Kahng, S. K., \& Crocker, J. (2004). Discreditable: stigma effects of revealing a mental illness history on test performance. Personality \& Social Psychology Bulletin, 30(7), 803-815. http://dx.doi.org/10.1177/0146167204264088

Rüsch, N., Corrigan, P. W., Todd, A. R., \& Bodenhausen, G. V. (2010). Implicit self-stigma in people with mental illness. Journal of Nervous and Mental Disease, 198, 150-153. 
http://dx.doi.org/10.1097/NMD.0b013e3181cc43b5

Scottish Government. (2009). Evaluation of 'see me' the National Scottish Campaign against the Stigma and Discrimination Associated with Mental Ill-Health. ISBN: 0755973699. Retrieved from http://www.scotland.gov.uk/Publications/2009/01/16153921/0

Scottish Government. (2012). Mental Health Strategy for Scotland: 2012-2015. Retrieved from http://www.scotland.gov.uk/Publications/2012/08/9714

Seymour, L. (2010). Common mental health problems and work: applying evidence to inform practice. Perspectives in Public Health, 130(2), 59-60. http://dx.doi.org/10.1177/1757913910363221

Shain, M., Arnold, I., \& Germann, K. (2012). The Road to Psychological Safety, Bulletin of Science, Technology \& Society, 32(2), 142-162. http://dx.doi.org/10.1177/0270467612455737

Simon, G. E., Revicki, D., Heiligenstein, J., Grothausa, L., VonKorffa, M., Katon, W. J., \& Hylan, T. R. (2000). Recovery from depression, work productivity, and health care costs among primary care patients. General Hospital Psychiatry, 22(3), 153-162. http://dx.doi.org/10.1016/S0163-8343(00)00072-4

Sinclair, A., \& Regan, S. (2007). Mental Health and Work, HR Network Paper MP75, Institute for Employment Studies, February, pp v-23.

Smith, R. M. (2006). Classroom management texts: A study in the representation and misrepresentation of students with disabilities. International Journal of Inclusive Education, 10(1), 91-104. http://dx.doi.org/10.1080/13603110500221545

Substance Abuse and Mental Health Services Administration (SAMHSA). (2010). Results from the 2009 National survey on drug use and health: Mental Health Findings (Office of Applied Studies), NSDUH Series H-39, HHS Publication No. SMA 10-4609). Rockville, MD.

Tsang, H. W. H., Angell, B., Corrigan, P. W., Lee, Y., Shi, K., Lam, C H., Jin, S., \& Fung, K. M. T. (2007). A cross-cultural study of employers' concerns about hiring people with psychotic disorder: implications for recovery. Social psychiatry and psychiatric epidemiology, 42(9), $723-733$. http://dx.doi.org/10.1007/s00127-007-0208-x

Unger, D. (2002). Employers' attitudes toward persons with disabilities in the workforce: myths or realties, Focus on Autism and Other Developmental Disabilities, Pro Ed Publications. http://dx.doi.org/10.1177/108835760201700101

Waghorn, G., Chant, D., Lloyd, C., \& Harris, M. G. (2009). Labour market conditions, labour force activity and prevalence of psychiatric disorders. Social Psychiatry Psychiatric Epidemiology, 44, 171-178. http://dx.doi.org/10.1007/s00127-008-0429-7

\section{Copyrights}

Copyright for this article is retained by the author(s), with first publication rights granted to the journal.

This is an open-access article distributed under the terms and conditions of the Creative Commons Attribution license (http://creativecommons.org/licenses/by/3.0/). 